
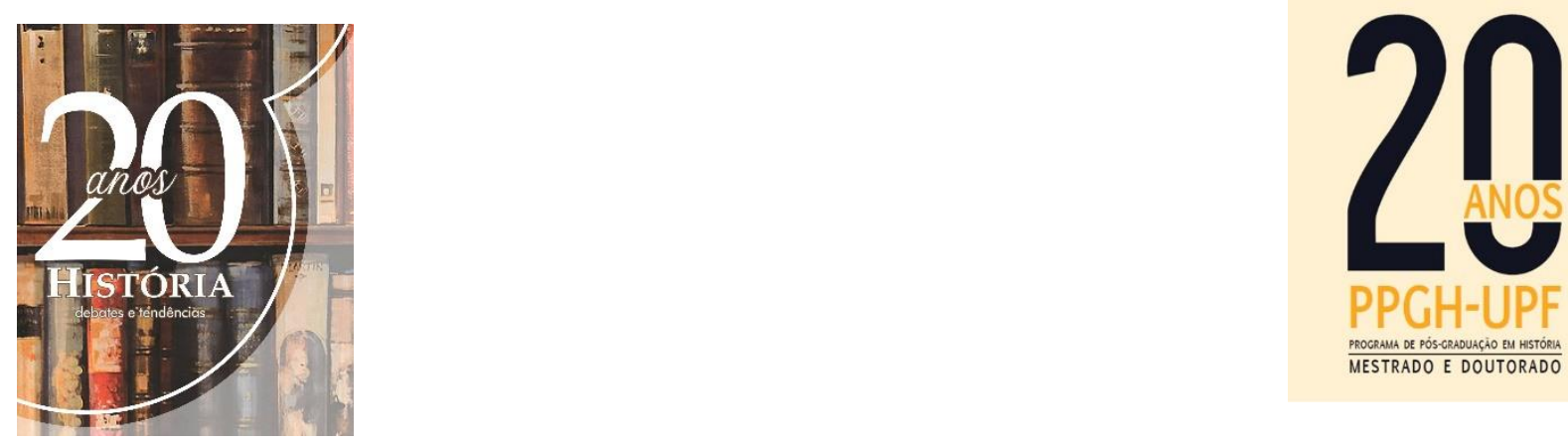

\title{
Sobre intereses agrarios y agroindustriales en la Argentina (1910-1960): representaciones históricas ${ }^{\mathrm{i}}$
}

\author{
Sobre interesses agrários e agroindustriais na Argentina (1910-1960): \\ Representações históricas
}

\author{
About Agrarian and Agro - industrial Interests in Argentina (1910 - 1960) \\ Historical Respresentations
}

\author{
Noemí Girbal-Blacha ${ }^{\mathrm{ii}}$
}

\begin{abstract}
Resumen: En la Argentina agroexportadora, la industria es sinónimo de agroindustria, en tanto expresión de las economías regionales, asociadas al desequilibrio territorial del país. La crisis mundial de los años '30 activa la industrialización sustitutiva de importaciones y el intervencionismo estatal. El dirigismo económico entre 1940 y 1950, se expresa en el Estado Benefactor y la redistribución del ingreso. El crédito oficial a las pequeñas y medianas industrias que producen para el mercado interno con materias primas nacionales, se expande hasta los años 50 cuando se promueve "la vuelta al campo". Este trabajo de historia regional analiza las representaciones acerca de los intereses corporativos agrarios y agroindustriales, desde el Estado entre 1910-1960, para sumar esta interpretación a la historiografía argentina. Palabras clave: Argentina. Agroindustrias. Region. Representaciones.
\end{abstract}

Resumo: Na Argentina agroexportadora, a indústria é sinônimo de agroindústria, uma expressão das economias regionais associadas ao desequilíbrio territorial do país. A crise mundial dos anos 1930 ativa a industrialização substitutiva de importações e o intervencionismo estatal. O direcionismo econômico entre 1940 e 1950 se expresa no Estado de bem-estar e na redistribuição de renda. $\mathrm{O}$ crédito oficial às pequenas e médias indústrias que produzem para $\mathrm{o}$ mercado interno com matérias-primas nacionais se expande até os anos 1950, quando se promove a "volta ao campo". Este trabalho de história regional analisa as representações acerca dos interesses corporativos agrários e agroindustriais a partir do Estado, entre 1910-1960, agregando esta interpretação à historiografía argentina.

Palavras-chave: Argentina. Agroindústrias. Região. Representações.

Abstract: In the agro-export Argentina, the industry is a synonoym of agrobusiness, an expression of regional economies, connected to the territorial imbalance of the country. The global crisis in the $30 \mathrm{~s}$ triggers the substitution industrialization of imports and state intervention. The economic dirigism between 1940 and 1950 is expressed in the Welfare State and the income redistribution. The official credit to the small and medium-sized industries that produce to the domestic market with national raw material, broadens to the 50s when "going back to the field" is encouraged. This research of regional history analyses the representations about the agrarian and agro-industrial corporate interests from the State between 1910 and 
1960 in order to add this interpretation to the Argentinian historiography.

Keywords: Argentina. Agroindustries. Region. Representations.

\section{Acerca de los sectores y representaciones del agro argentino}

La Argentina agroexportadora se consolida en las últimas décadas del siglo XIX y la industria se asocia - hasta las primeras décadas del siglo XX - con el sector agrario. El frigorífico, la lechería y los molinos harineros, en la región pampeana; los ingenios azucareros, en el Noroeste, la industria yerbatera y taninera en el Nordeste y las bodegas vitivinícolas, en la región cuyana del Oeste cordillerano, son algunas expresiones tempranas de las economías regionales, cuyas representaciones se asocian al desequilibrio territorial del país. Durante los años de 1920 la expansión del girasol en Buenos Aires y del algodón en el Nordeste chaqueño de la Argentina alimentan - en parte - la industria aceitera, en el primer caso, y una acotada actividad textil, en el segundo (MANZANAL; NEIMAN; LATTUADA, 2006).

La crisis mundial de los años '30 que afecta al mundo occidental y especialmente a América Latina, activa en la Argentina la industrialización sustitutiva de importaciones signada por el intervencionismo estatal en la economía y la sociedad, promoviendo alternativas para el mercado interno pero sin abandonar el perfil agrario. Las juntas reguladoras de la producción agroindustrial toman posición en el escenario político-económico, mientras el sistema financiero acompaña las transformaciones desde 1931 con el Control de Cambios (reformado en 1933) y desde 1935 con el Banco Central de la República Argentina, para sostener a los grandes intereses del campo y de la agroindustria.

La regulación y el dirigismo económico se expresan en las décadas de 1940 y 1950, cuando avanza la presencia del Estado Benefactor, la redistribución del ingreso y al mercadointernismo. El crédito oficial a las pequeñas y medianas industrias que producen para el mercado interno con materias primas nacionales se extiende hasta los años '50. Entonces la economía nacional y popular peronista promueve "la vuelta al campo""; trascendiendo la caída de Perón y más allá del intento de asociación de los pequeños y medianos industriales en la Confederación General Económica (CGE) en 1953. Al mismo tiempo, las grandes corporaciones rurales (Sociedad Rural Argentina) y agroindustriales (Unión Industrial Argentina, Centro Azucarero Nacional, Centro Vitivinícola Nacional) dan muestras de su poder más allá de los cambios institucionales que vive el país. 
Este trabajo se propone analizar, en este complejo escenario nacional - desde el Centenario y hasta mediados del siglo XX - las representaciones que se tienen desde el Estado acerca de los intereses corporativos agrarios y agroindustriales; considerando que la fenomenología de la memoria, la epistemología de la historia y la hermenéutica histórica, forman parte de una problemática común: la representación del pasado (VOVELLE, 1999, p. 45-49). El propósito es sumar esta interpretación a los estudios que abordan la compleja relación agro-industria como parte del discurso estatal y las políticas públicas.

\section{Intereses rurales y agroindustriales corporativos entre el Centenario y 1930}

Un sector de la elite dirigente - los llamados liberales reformistas - inician hacia 1900 un proceso de autocrítica (ZIMMERMANN, 1994). Creen que es preciso hacer concesiones desde la cúpula del poder para contrarrestar los efectos de la "cuestión social". El ministro del Interior del Presidente Julio A. Roca, Joaquín V. González, junto a otros "notables", rescata la importancia de los partidos políticos en esa apertura propuesta. En 1902 se sanciona la ley de reforma electoral, pero la dirigencia argentina no renuncia al ejercicio del control social y en ese mismo año se sanciona y aplica la Ley de Residencia, que expulsa del país a todo extranjero que perturbe el orden público. La dirigencia nacional agrupada en sus corporaciones más tradicionales, descubren los aspectos negativos de la inmigración (PANETTIERI, 1966).

La Argentina, inmersa en un proceso de urbanización creciente, asiste desde fines del siglo XIX al crecimiento de los sectores medios y bajos de la población que no se sienten representados por la vieja guardia política y sus métodos (BOTANA, 1977). La Unión Cívica Radical (UCR) - nacida en 1891 - capitaliza este caudal electoral, cuando en 1910 su líder, Hipólito Yrigoyen, sella un compromiso con el flamante Presidente de la Nación Roque Sáenz Peña, renunciando a la conspiración. El titular del Ejecutivo se dispone a garantizar la democracia electoral a través de una legislación que consagra el voto individual, secreto y obligatorio para los varones mayores de 18 años nativos o naturalizados. En 1916 el triunfo de Yrigoyen queda asegurado. El respeto a la Constitución Nacional y a la democracia son los estandartes de la multiclasista UCR (ROCK, 1977).

El "obrerismo" yrigoyenista provoca desconfianza en la elite dirigente. Los empresarios rurales y agroindustriales que concentran una alta cuota de poder en la Argentina agroexportadora, se agrupan desde fines del siglo XIX en entidades corporativas para reforzar 
su operatividad frente a otros grupos y frente al Estado, que a su vez se respalda en ellos. La Sociedad Rural Argentina (1866), la Unión Industrial Argentina (1887), el Centro Azucarero Nacional (1894), el Centro Vitivinícola Nacional (1905), son algunas muestras representativas de la alianza de estos intereses sectoriales surgidos en tiempos de la Argentina Moderna y positivista. La nueva coyuntura obliga a estrechar filas para mantener el control social frente al oficialismo, especialmente cuando no existe un fuerte partido conservador ni continuidad en el ejercicio gubernativo. De todos modos, el radicalismo gobernante no propondrá cambios en el modelo económico, más allá de una redistribución de los ingresos. Se sigue respaldando a la Argentina agropecuaria (GIRBAL-BLACHA, 2003, p. 367-395).

El estallido de la conflagración mundial (1914) pone en juego una nueva estrategia empresaria. Las más importantes corporaciones y empresas radicadas en el país se agrupan, en 1916, en la Confederación Argentina del Comercio, la Industria y la Producción (CACIP), para evaluar los efectos de la guerra en la economía nacional. Los coletazos de la Revolución Rusa (1917) en el contexto de un gobierno representativo de los sectores medios y bajos de la sociedad son temidos por "los notables" y los agroindustriales, por sus repercusiones en el clima social. En 1918 se crea la Asociación Nacional del Trabajo; una corporación de empresarios preocupados por proveerse de mano de obra ante las recurrentes huelgas (OSPITAL, 1994). Las representaciones que el Estado tiene de los intereses patronales - más allá de la democracia vigente - encaja en esta perspectiva de la realidad que forjan los sectores empresariales desde las distintas corporaciones.

Las revueltas de peones rurales y arrendatarios durante 1918, ponen en guardia a la Sociedad Rural y aun a la Federación Agraria Argentina, entidad que desde 1912 nuclea a los arrendatarios. En enero de 1919 los sucesos violentos de la llamada "Semana Trágica" promueven en las corporaciones empresarias "mano dura" ante las huelgas y atentados. La dirigencia política desplazada de las funciones de gobierno, se suma al reclamo desde otras entidades corporativas como la Liga Patriótica Argentina (1919), que bajo el lema "Orden y Patria", apela a la defensa de la "familia castellana honesta" donde cree encontrar las raíces de la identidad nacional (BARBERO; DEVOTO, 1983). Las brigadas femeninas de la Liga recorren los pueblos de la campaña y despliegan la "autoridad moralizadora" del nacionalismo doctrinario de elite. El discurso contra el inmigrante y su influencia en la descomposición social, abunda y se acude a las fuerzas armadas para recomponer el orden social (GIRBAL-BLACHA, 2018, p. 139-151).

Desde fines del siglo XIX la diversificación del riesgo económico empresarial orienta las inversiones del sector, con respaldo estatal, legislación amplia y crédito oficial barato. La 
formación de sociedades anónimas capitaliza a las empresas y disminuye sus riesgos de inversión. Los agroindustriales del azúcar y vitivinicultores son referentes en la materia, desde 1895 cuando se crea la Compañía Azucarera Tucumana S. A. en el primer caso, y desde 1907 los segundos, con las Sociedades Anónimas Giol, Arizu y Tomba. A ellas se añaden acciones concretas para obtener corporativamente subsidios o exenciones impositivas del gobierno nacional, ya que los erarios provinciales dependen de estas monoproducciones (BRAVO, 2017, p. 69-98). La representación agroindustrial es reforzada por el poder central que no resulta ajeno a estos intereses.

Los empresarios asociados al sector rural comprenden la necesidad de ampliar sus inversiones a rubros complementarios. En la región pampeana invierten parte de sus dividendos en compañías aseguradoras (contra el granizo, las plagas, etc.), o en industrias subsidiarias que complementan su actividad principal (refinerías, acciones en frigoríficos y ferrocarriles). Pero también hay quienes deciden invertir parte de su capital en actividades agrarias de las regiones marginales de los Territorios Nacionales, donde se radicara el indígena hasta casi el filo del siglo XX, marcando la ausencia de una burguesía capaz de construir el espacio en defensa de los intereses locales (GUY, 1982, p. 351-374; GIRBAL-BLACHA, 1994, p. 107-122; MANZANAL; ARZENO; NUSSBAUMER, 2007).

Es el caso de la explotación forestal en el Gran Chaco Argentino, con sus dos subregiones: 1) el Chaco santafesino situado al Este e integrado por el Norte de Santa Fe, Chaco y Formosa; así como 2) el Chaco santiagueño en la porción Oeste de la región e integrado por Santiago del Estero y el Este de Tucumán y Salta, dedicadas a la explotación de la madera dura (algarrobo, quebracho). La primera es importante por la riqueza taninera de su quebracho y atrae la inversión del capital extranjero; siendo The Forestal Land, Timber and Railways Ltd. de capitales ingleses y alemanes - su máxima expresión desde 1905. En el Chaco santiagueño, en cambio, los capitales nacionales procedentes del litoral o de la región del Tucumán son atraídos por la explotación boscosa penetrada por el ferrocarril, para la producción de postes, durmientes y leña.

En el Chaco santiagueño se asienta una de las manifestaciones más significativas de la diversificación inversora de los importadores, exportadores y estancieros del eje metropolitano. El interés inversor en esta zona reconoce sus antecedentes en la expedición Bouchard a los Campos del Cielo (región boscosa de Santiago del Estero) durante 1899 y otra encabezada por el empresario Luis Zuberbühler como líder de un importante sindicato inversor que compra 1.000 leguas de ese campo para explotar madera dura, subdividirlo en estancias medianas una vez desmontado y dedicarlo a la ganadería criolla. Para poder practicar la explotación maderera, 
el ferrocarril se hace indispensable. En 1902, por acción de uno de los empresarios y financistas más ricos del país, Ernesto Tornquist, la Sociedad Belga Argentina comienza la extensión de rieles en territorio santiagueño.

Con capitales, rieles, crédito oficial barato y los recursos naturales a disposición de los empresarios, no extraña que en 1905 se constituya la Sociedad Anónima Quebrachales Chaqueños formada para la compra venta de tierras y para explotar los bosques de Santiago del Estero y del Chaco, con un capital de más de 4 millones de pesos, núcleo de importantes capitalistas vinculados al comercio litoraleño. ${ }^{\text {iii }}$ Los aserraderos de Quimilí y Alhuampa concentran las actividades de esta sociedad anónima que en 1912 - ya explotada la madera de la zona - entra en liquidación y fracciona los campos para la venta en pequeñas estancias. En 1906 se constituye una nueva Sociedad Anónima, Quebrachales Tintina, del grupo Tornquist. ${ }^{\text {iv }}$ Se conforma sobre 220 leguas de tierra comprada al costo al sindicato liderado por Luis Zuberbühler. Preside la nueva empresa Ernesto Tornquist, con un capital social de un millón de pesos oro y dispuesta a operar en los bosques santiagueños, en el negocio de tierras, formación de establecimientos ganaderos y explotación y aprovisionamiento de leña - frente a la escasez de carbón durante la Guerra - para los ingenios tucumanos, en los cuales el mismo Tornquist tiene intereses comprometidos. La compañía prospera, mientras el espacio regional es depredado, sin reinversión en la zona (GIRBAL-BLACHA, 2011).

El obraje es la base de esta actividad extractiva, con aserraderos fácilmente desmontables y de bajo costo que dan vida a este núcleo urbano forestal levantado en los puntos de embarque y en las cercanías del ferrocarril, contando con mano de obra nativa que padece el rigor del control social ligado a condiciones laborales alejadas de todo marco legal. Surgen Suncho Corral, Quimilí, Tintina, Campo Gallo, como poblaciones que crecen y decaen junto con la explotación boscosa (GIRBAL-BLACHA, 1993, p. 29-57). El obraje no radica población estable ni contrarresta la depredación forestal; por el contrario, se auspicia una penetración extensiva en la cuña boscosa protegiendo los intereses particulares. ${ }^{\mathrm{v}}$

Las estrategias patronales se adaptan a los desajustes de la economía agroexportadora argentina y desde los años '10 al fin de la expansión horizontal agraria; los capitalistas de la rica región pampeana diversifican sus inversiones y minimizan sus riesgos. Sus fortunas se consolidan, pero no las economías marginales, de donde esos actores sociales obtienen importantes ganancias, sin reinvertirlas en los centros de producción de esas zonas postergadas. El aparato estatal no es un simple observador. Acompaña estas mutaciones de las representaciones rurales y se ajusta a ellas. 
Durante los años '30 el Estado y los sectores empresarios se asocian para conocer y contener la desocupación, considerada impulsora de la mendicidad y la vagancia. La organización del trabajo pasa a ser el eje de las discusiones y se auspician medidas distributivas para los trabajadores sin ocupación (ASCOLANI, 2009, p. 36-48). El paro forzoso es cuestionado y revisado en sus causas. En consonancia con los tiempos se pretende contrarrestarlo a través de una intervención reguladora estatal directa. El Censo de Desocupados de 1932 y la acción de la Junta Nacional para Combatir la Desocupación desde 1935, son expresiones de esas inquietudes de la dirigencia nacional.

\section{El Estado interventor, los subsidios a la agroindustria y las representaciones sobre el agro}

Los efectos del crac neoyorkino de 1929 y la ruptura del orden institucional en la Argentina de setiembre de 1930, ubica al poder político y económico en el marco de un "heterogéneo universo nacionalista" (FINCHELSTEIN, 2002). En materia económica son tiempos de bajos precios internacionales para los productos agrícolas, restricción en las importaciones que promueven la industrialización para sustituirlas y migraciones internas del campo a la ciudad que alientan el temido desempleo y reactivan las estrategias patronales y del propio Estado para evitar sus temidas consecuencias e imponer el control social (O'CONNELL, 1984, p. 479-514; ASCOLANI, 2009, p. 111-166).

Los empresarios del agro, diversificados corporativamente al impulso de la crisis (en 1932 se forma CARBAP que representa a los criadores de Buenos Aires y La Pampa y dos años después la CAP, Corporación Argentina de Productores de Carnes) redoblan su apuesta para exigirle soluciones al Estado, que aumenta su intervencionismo, para preservar el perfil agrario del país. A partir de 1932 y durante gran parte de la década del '30 el gobierno nacional impulsa la creación de las Juntas Reguladoras de la producción: de Carnes, de Granos, del Azúcar, de Vinos, de Yerba Mate, Nacional del Algodón, para subsidiar al agro y sostener a los productores, pagando precios por encima de los que fija el mercado internacional, evitando la desinversión. Con excepción de la Junta Nacional del Algodón que impulsa el cultivo para dar sustento a la industria textil argentina, el resto tiene por objeto regular la venta de los productos y sostener los precios que se pagan a los productores, para evitar la deserción en el medio rural.

Mientras el Estado se hace cargo de subsidiar a los empresarios y productores rurales, es sencillo advertir un cambio unilateral en las estrategias empresariales, que refuerzan su 
carácter corporativo para acercarse al poder político que mantiene los perfiles significativos de las representaciones agroindustriales del empresariado. Este se enriquece amparado en la intervención oficial y mientras las regiones marginales acentúan su postergación. Es una Argentina que alienta la industrialización sustitutiva de importaciones como una oportunidad alternativa, pero colateral al país agrario.

El control social sigue formando parte de las preocupaciones más importantes del gobierno y del sector empresario, quienes reciben entonces la influencia del nacionalismo y del movimiento católico (ZANATTA, 1996). La crisis acentúa el desempleo y el Estado interventor junto a los grandes empresarios ponen en funcionamiento, a partir de mayo de 1935, la Junta Nacional para Combatir la Desocupación. El objetivo es de control y ayuda social hasta 1944, cuando un decreto - del gobierno pre peronista del GOU - anule los alcances de la ley 11.896 que la creara, en agosto de 1934 (GIRBAL-BLACHA, 2003, p. 25-53).

Desde sus inicios la Junta actúa en connivencia con el discurso del empresariado agroindustrial. ${ }^{\text {vi }}$ Estudia el carácter y los alcances del paro forzoso en el país, para encontrar "no solamente soluciones transitorias que podrían reclamarse en un momento, sino también las causas más profundas, y algunas de ellas de carácter permanente aunque atenuado en sus efectos, que tiene el problema de la desocupación en la Argentina". Cumple funciones de ayuda inmediata, sin descuidar "las soluciones de fondo", para evitar "improvisaciones inconducentes". vii

El plan de acción de la Junta para erradicar el desempleo, no es innovador; recoge experiencias anteriores aplicadas en el país y practica la exclusión como instrumento corrector, ajustándose a las exigencias del empresariado agrario y agroindustrial. El traslado esporádico de braceros y su reubicación transitoria es una de las actividades más frecuentes de la Junta. En general, su propuesta consiste en: procurar asistencia inmediata y práctica a los desocupados indigentes; facilitar el traslado de obreros, jornaleros o peones sin trabajo desde las zonas donde existe oferta de brazos a las que carecen de ellos; capacitar a los desocupados sin profesión, impartiéndoles nociones sobre oficios mecánicos o rurales; auspiciar la adopción de medidas gubernativas para una mayor demanda de trabajo; estudiar la manera práctica de establecer colonias agrícolas; y concentrar en campos especiales a los desocupados sin aptitudes ni deseos de trabajar. Las representaciones de los grandes sectores empresarios del campo argentino se mantienen, aun ante la mirada de un Estado que las reconoce y respalda. ${ }^{\text {viii }}$

La represión de la vagancia y la mendicidad - entendidas como derivados del desempleo - es otro de los fines de la Junta: 
Que en cuanto ellas pudieran ser una consecuencia de una deficiente formación de la juventud, parte de la responsabilidad corresponde a los padres y tutores que descuidan la orientación vocacional de sus hijos, y otra a la escasez en nuestro país de establecimientos de educación práctica que faciliten el aprendizaje de un oficio o profesión útil. ${ }^{\text {ix }}$

Ambas son consideradas "un mal social", exigiendo una rápida solución a los poderes públicos; mientras tanto se apela al uso de la disciplina. Como desde los tiempos de la "Generación del 80", la disciplina en el albergue de desocupados que está a cargo de la Junta en la zona capitalina de Puerto Nuevo, es una exigencia fundamental para contener "la diversidad de razas y de cultura" - dice - así como las "condiciones de vida precaria de la población". x Poco a poco las funciones de la corporación se transforman y tiende a convertirse, acorde a los tiempos y como ella misma lo manifiesta en 1937, en una Junta Reguladora del Trabajo.

Una respuesta simple para una situación compleja, que se prolonga en el tiempo y promueve en el empresariado acciones tradicionales y empeñadas en salvaguardar el poder que ellos mismos concentran. Estas y otras cuestiones derivadas dan lugar a la "Encuesta sobre la desocupación en la Argentina", remitida a los gobernadores por la Junta, el 8 de abril de 1937. El propósito es reunir datos de los jornaleros u obreros desocupados y encontrar alguna alternativa ocupacional. En cada caso las respuestas de las autoridades son variadas conforme a sus realidades zonales, pero en todas ellas el desplazamiento de mano de obra - a cargo del gobierno - parece ser el común denominador, tanto como la denuncia de falta de pequeños y medianos emprendimientos capaces de arraigar a la población lugareña. Es una forma de presión del empresariado rural sobre el Estado, que ejercita una vieja práctica, aunque aparezca renovada en sus formas de expresión.

Desde la provincia norteña de Santiago del Estero, con una importante riqueza forestal diezmada, se afirma - por ejemplo - que:

la vida de trabajo del obrero santiagueño no es la del hombre civilizado. Son deficientes las condiciones de higiene y seguridad en que desarrolla su labor, en una atmósfera de inseguridad y de peligro, aunque familiarizado con ella. Sus consecuencias son realmente de carácter pavoroso; la mortalidad obrera - "capital humano" - acusa porcentajes que exceden todo cálculo e indican la necesidad imperiosa de que el Estado acuda a combatir el mal, salvando de la decadencia a una raza ya en principio de degeneración. ${ }^{\mathrm{xi}}$

Jornadas laborales largas, salarios míseros y nominales, explotación de parte del obrajero o el gran ganadero, recargo en el precio de las mercaderías, hacen miserable la vida de 
este obrero. "Los patrones mantienen un régimen económico a fin de asegurarse los déficits y el caudal de energía humana necesarios para la explotación, y favorecidos por el aislamiento que los coloca fuera de todo control eficaz, convierten poblaciones enteras, de más de 100 mil hogares, en tributarios forzosos de la industria, mediante condiciones que revisten el carácter de una verdadera esclavitud". xii

Las revelaciones de la encuesta brindan un diagnóstico interesante para sustentar la labor de la Junta Nacional para Combatir la Desocupación y la del propio Estado intervencionista, así como para orientar las estrategias del sector empresario vinculado al agro y a las agroindustrias. La Conferencia realizada en Mendoza, en 1938, discute posibles soluciones a las causas y efectos del desempleo, no apartándose demasiado de las clásicas respuestas dadas en décadas anteriores. La desocupación es vista, en el país, como "eminentemente agrícola"xiii y se considera que el problema debe desaparecer con recetas coactivas, es decir, "mediante la aplicación de recursos que exigen cierta energía". xiv

¿Cuál es la propuesta patronal para revertir las causas más profundas del desempleo?. No muy variadas y atadas a sus tradicionales representaciones del tema: 1) obras públicas nacionales para absorber mano de obra; y 2) la intervención del Estado, "como agente rectificador de las fuentes de ocupación que existen en el presente". La explicación dada frente a este problema muestra el perfil ideológico de no pocos empresarios, expresado a través de la Junta:

El mal de la pluralidad de labores remuneradas separadamente es de fácil corrección. Sólo exige un tratamiento enérgico. Hitler, en Alemania, cuando asumió el poder, halló el elenco burocrático excesivamente abultado. [...] La energía que caracteriza al estadista alemán pronto terminó con ese estado de cosas, y en los días que corren, desde hace años, se observa un régimen estricto en todo el país, así en las actividades privadas como en las públicas: nadie puede, en Alemania, ocupar más de un puesto ni percibir más de un sueldo. ${ }^{\mathrm{xv}}$

Los patrones creen - dice - que entre nosotros sólo bastaría con aplicar las disposiciones existentes para obtener esos resultados. Resulta evidente la perdurabilidad de las viejas recetas para revertir este agudo problema argentino. Las más novedosas - aunque significativas - pasan inadvertidas. Así ocurre con la proposición elevada por la provincia de Salta, declarando como "una necesidad ineludible e impostergable la sanción de leyes creando la Subsecretaría del Trabajo y Asistencia y organización del Consejo Nacional del Trabajo", dependientes del Ministerio del Interior de la Nación. ${ }^{x i}$ Para el Presidente de la Junta - el hacendado Eduardo Crespo - en su discurso de clausura del encuentro, "en la República Argentina no hay problema 
de desocupación profunda, aunque pueda haber desocupados"; existe en su opinión "una mala coordinación del trabajo, que puede evitarse". ${ }^{\text {xii }}$

Como en tiempos del Centenario esta dirigencia no renuncia a responsabilizar de la crisis y el malestar social, al inmigrante, reclamando la intervención estatal. Desde la región azucarera del Norte argentino, el empresariado y el gobierno proponen que "hay que defender al nativo contra el extranjero de condición inferior que en épocas de zafra se infiltra en la República en cantidades considerables, desalojando al criollo, porque su nivel de vida es aún más bajo que el de éste. Hay que organizar el trabajo, para que los asalariados sean retribuidos en forma de cubrir sus necesidades y les quede un margen de bienestar material y moral, ya que son argentinos dignos de toda nuestra preocupación, continuadores de nuestra raza y de nuestros ideales". xviii

La Junta se apresta a desplegar - desde marzo de 1939 - una acción de "bien público", producto de "gentes capacitadas" que cumplan con el designio específico de "estructurar las bases del trabajo coordinado en la República", para contrarrestar la desocupación. Se considera "imprescindible iniciar cuanto antes una política gubernamental que se traduzca en una vuelta al campo, completada con un cambio sustancial en el régimen educativo de la población rural que abandona la campaña". ${ }^{x}$ Como en los '20 vuelve al escenario histórico el concepto instrumental "de los que mandan", sobre la función social de la tierra (BLACHA, 2015). ${ }^{\mathrm{xx}}$

Para 1940 la dirigencia nacional (agraria, industrial y política) comienza a referirse a la necesidad de alentar "cambios estructurales", que comprendan el desarrollo del mercado interno. Frente a la desaceleración del crecimiento y la necesidad de una mayor diversificación de las fuentes más dinámicas de esa expansión, se hacen explícitas las medidas para un cambio acotado. El ministro de Hacienda, Federico Pinedo, presenta ante el Congreso Nacional - para anticiparse a los efectos de la posguerra - el Plan de Reactivación de la Economía Nacional. Propuesta pro-aliada, considerada como el primer documento de Estado donde se intenta modificar parcialmente la estrategia de desarrollo económico vigente. Es de carácter industrialista, procura conciliar industrialización y economía abierta, intenta fomentar el comercio con los Estados Unidos y crear un mercado de capitales. Alienta un programa de préstamos industriales, la construcción de viviendas, la revisión de las tarifas aduaneras y la adquisición por parte del gobierno de los saldos exportables agrícolas no colocados En síntesis, se decide mantener abierta la economía "oficializando" la industrialización, pero dejando establecido que el agro sigue siendo "la gran rueda de la economía" y que las industrias 
actuarían como engranajes secundarios, cuyo funcionamiento se activaría cuando aquélla ofreciera dificultades (LLACH, 1984, p. 515-558).

La propuesta de Pinedo da cuenta de la creciente hegemonía de las posiciones industrialistas, de las dificultades por las que atraviesa el comercio internacional y de la necesidad de dinamizar la demanda interna. La acción estatal es vista como la única alternativa. El tránsito del intervencionismo al dirigismo estatal en la economía avanza, pero la falta de apoyo político hace naufragar el plan propuesto; "modernizante" pero tardío. Queda al descubierto la importancia del mercadointernismo más allá del Estado, entre los empresarios, militares, obreros e intelectuales. Aunque a la Argentina le haya sido difícil lograr una estrategia de industrialización perdurable, entre 1940 y 1943 se dictan varias leyes para su promoción atendiendo a las exigencias del mercado interno. En 1943 se crea el Banco de Crédito Industrial Argentino, liderado por el empresario de la industria de envases de hojalata Miguel Miranda (durante parte de la gestión peronista Presidente del Banco Central) y al año siguiente, se convierte en Secretaría la Dirección de Industria y Comercio (GIRBAL-BLACHA, 2000, p. 77102).

Los cambios llevan a los empresarios del agro a reorganizarse y el 24 de febrero de 1943 fundan Confederaciones Rurales Argentinas (CRA), reforzando la corporativización. Más allá del frustrado Plan Pinedo, el país sigue esperando "la vuelta a la normalidad", aunque no pueda definirla con certeza. Entre 1930-1943, rige una política de contraste que se enlaza a la vulnerabilidad propia de una economía abierta como la argentina. Desde el poder se procura restaurar la hegemonía agroexportadora, frente a un comercio mundial limitado. Por otro lado, se destaca el aumento del sector industrial en medio de bajas tasas de inversión (FERRER; ROUGIER, 2008, p. 275-288). En todo el período hay dos grandes sectores sociales ausentes, paradójicamente los más desarrollados merced a las nuevas condiciones económicas: la pequeña y mediana burguesía industrial y la clase obrera, quienes no encuentran representación en ninguna de las fuerzas políticas de la Argentina (DE IMAZ, 1965, p. 184-250). A la alianza entre ambos sectores apelará Juan Perón, para construir la red de apoyo a su gobierno.

En noviembre de 1943 el decreto ley 14.001 se hace eco de los reclamos de los arrendatarios y concede una rebaja obligatoria del 20\% en el precio de los arriendos; al mismo tiempo, mantiene en vigencia la prórroga de contratos y la suspensión de los desalojo conforme a la ley 12.771 de 1942. La Federación Agraria Argentina se entusiasma con estas medidas, porque las considera un avance hacia "la tierra para quien la ocupa y la trabaja" como lo venía proponiendo desde 1918, y que a partir de 1944 es impulsada por el Consejo Agrario Nacional creado en 1940, mediante algunas expropiaciones en tierras de regular productividad. 
La estrategia implementada para una - finalmente frustrada - "reforma agraria", impulsa la desinversión en el campo, ante la ausencia de definiciones (BLANCO, 2007, p. 211 316; LAZZARO, 2008, p. 361-380). Proliferan las sociedades anónimas agrarias, constituidas desde la segunda mitad de los años '40, con la participación de familiares de los propietarios originales, que la Federación Agraria Argentina denuncia como "simulación del fraccionamiento de los latifundios". Se acelera la división de grandes propiedades rurales en explotaciones medianas. A través de esa argucia que las exime del pago del impuesto a la herencia, los titulares consiguen conservar la propiedad mediante acciones innominadas. Se anticipan a los efectos de una posible reforma en el sistema de tenencia de la tierra, que el mismo Perón parece dispuesto a realizar durante su campaña electoral. ${ }^{\mathrm{xi}}$ Una vez más el empresariado rural modifica su estrategia para adaptarse a los tiempos y refuerza las representaciones históricas que lo sustentan y le dan permanencia en el tiempo (LATTUADA, 1986).

El Estatuto del Peón Rural de 1944, reglamentando las condiciones laborales de los asalariados agrarios permanentes, el Estatuto del Tambero-Mediero de 1946, la atención prestada al Centro de Oficios Varios para sindicalizar a los peones estacionales o transitorios, así como la propuesta de reforma agraria desde el Consejo Agrario Nacional a través de las figuras de Antonio Molinari y Mauricio Birabent, que incluye - en 1945 - la entrega de títulos de propiedad, algunas expropiaciones y un gran despliegue propagandístico, son decisiones que aunque adoptadas antes de 1946, el peronismo hace suyas. El mensaje peronista de la primera hora postula que "la tierra no debe ser un bien de renta, sino un bien de trabajo". xxii

El discurso amenazante se contradice con los hechos del gobierno nacional. La titularidad de la cartera de agricultura entre 1946-1947, está en manos del hacendado Juan Carlos Picazo Elordy, un hombre de la Sociedad Rural Argentina (SABATO, 1989; SIDICARO, 1982, p. 51-104). Quien lo sucede, el ingeniero agrónomo Carlos Alberto Emery, está vinculado al poder agrario; pertenece a la Asociación de Criadores de Ganado Holando Argentino y se desempeña en la prestigiosa usina de productos lácteos "La Vascongada“. Varios miembros del Directorio del Banco de la Nación Argentina pertenecen simultáneamente a las comisiones directivas de la Corporación Argentina de Productores de Carnes (CAP) y del importante frigorífico Sansinena de capital inglés, por ejemplo (REIN, 1998) . Las reformas sociales dirigidas a beneficiar a los sectores más bajos del campo son presentadas por el Ejecutivo Nacional como indispensables para la evolución de la empresa agraria, amortiguando potenciales conflictos (LATTUADA, 1986, p. 105-136). 
Juan Domingo Perón, desde el gobierno nacional, entiende que para ejecutar su política económica redistributiva del ingreso necesita sostener una producción agropecuaria creciente y minimizar el conflicto social. Le otorga entonces al Instituto Argentino para la Promoción del Intercambio (I.A.P.I.) amplios poderes, permitiéndole comercializar con exclusividad la producción agraria, comprando a precios mínimos al productor y vendiendo en un mercado mundial que paga precios altos por los cereales. La diferencia obtenida suministra el capital para implementar una política crediticia genuina que, a partir de la reforma bancaria de 1946 que nacionaliza la banca y los depósitos, responde a los objetivos del Estado (NOVICK, 1986; ROUGIER, 2012). De todos modos, más allá del diálogo tenso entre el Estado y los grandes agroindustriales que parecen no encajar en la "Nueva Argentina" de Perón, el crédito oficial fluye también hacia esos sectores. ${ }^{x x i i i}$ La coordinación de intereses, la concertación socio rural y el compromiso del poder político para sustentar al campo, sigue formando parte de las estrategias vigentes, más allá de la confrontación discursiva.

El Banco de la Nación Argentina, el Banco de Crédito Industrial Argentino, el Banco Hipotecario Nacional y el Banco de la Provincia de Buenos Aires, dan cuenta del respaldo crediticio no sólo a los sectores populares, sino a la elite empresaria y terrateniente argentina (BELLINI; ROUGIER, 2008). El beneficio del crédito rural de habilitación (de bajo interés y largo plazo de reintegro) dirigido a los pequeños productores, también llega - desde 1950 - a estancieros, frigoríficos, exportadores de cereales, consignatarios, compañías inmobiliarias y grandes productores, quienes siguen diversificando sus inversiones en otros rubros de la actividad económica o en el mismo, pero en regiones marginales. Todos ellos - más allá de la confrontación política - reciben el auxilio de la banca oficial.

Los bajos precios que el I.A.P.I. paga a los productores rurales, la prórroga de contratos de arrendamiento, el congelamiento de los cánones pagados por el arriendo de los campos y el aumento de los salarios rurales, distorsionan las relaciones en el campo y se reflejan en el decrecimiento del área sembrada y en la división de posturas del sector rural frente al proceder estatal. Parte de ese deterioro es reparado por el apoyo financiero oficial y el hecho ponderable en el balance de interrelaciones vinculado con la diversificación inversora de la cúpula agraria.

Entre 1949-1950 las condiciones internacionales se modifican y el plan quinquenal peronista muestra sus limitaciones. Los sectores rurales endurecen sus reclamos. En 1949 la Constitución Nacional se reforma y también la Carta Orgánica del Banco Central de la República Argentina. Desde entonces se permite la emisión de moneda sin el resguardo del respaldo en metálico. Se abre un ciclo económico diferente para la "Nueva Argentina" (FISZBEIN, 2010, p. 15-50) con la presencia sostenida de la inflación y sus secuelas sobre la 
producción y el nivel de vida. Mayor producción, aumento del ahorro interno y menor consumo es la consigna gubernamental del momento, para satisfacción del empresariado agroindustrial. ${ }^{\text {xxiv }}$

Son tiempos de "cambio de rumbo " y con él de la "vuelta al campo”. La irrupción de la producción granífera de los Estados Unidos y Canadá en el mercado mundial provoca, hacia 1950, una caída en sus precios internacionales. Los altos beneficios que el I.A.P.I. obtiene, se restringen. La economía argentina se hace más liberal e incentiva el agro y a sus empresarios más tradicionales. El Estado peronista revisa la "tercera posición " admitiendo la inversión externa. El discurso oficial matiza su lenguaje para captar los diversos intereses del campo argentino.

Al inaugurar la sesiones legislativas, el $1^{\circ}$ de mayo de 1950, el Presidente Juan Perón advierte, para beneplácito del empresariado, que "el sentido de nuestra independencia económica no es de orden aislacionista" y añade - al tiempo que descalifica las críticas opositoras - que "todo cuanto hemos hecho ha sido precisamente para asegurar un promisorio porvenir a la economía agropecuaria". ${ }^{x x}$ El Banco de la Nación Argentina acompaña el discurso con el crédito a favor de estos sectores económicos productivos de alta escala. "El campo argentino es aun, y lo será sin duda a través de muchas generaciones más, el pilar sustancial de la economía nacional, a cuyo flujo y reflujo quedan condicionados todos los demás factores de la organización hacendal", afirma el Presidente de la entidad, quien al mismo tiempo declara que la concesión de créditos al sector rural se ha extendido como parte de las decisiones políticas oficiales que favorecen "a firmas de escasa o ninguna responsabilidad material, pero de reconocida capacidad y solvencia moral". xxvi

La economía argentina de los años de 1950 se contrae ante los cambios coyunturales externos e internos. Las entidades empresariales del agro aprovechan la oportunidad y no tardan en elevar un Memorial al Presidente Perón refiriéndose a la "situación lesiva del ordenamiento jurídico-económico-social imperante", en una actitud que compromete al accionar gubernamental, apercibido ya de la necesidad de readecuar su orientación económica. El Estado auspicia la mecanización agrícola, aumenta los precios pagados a los productores y rescata la importancia del cooperativismo agrario, como instrumento para reducir los costos de intermediación. El discurso y el crédito oficial se adecuan a los tiempos. ${ }^{\text {xxvii }}$ Los empresarios del agro ordenan sus estrategias para adecuarlas a una mayor heterogeneidad de la sociedad rural y reorganizar sus acciones corporativas. Para el poder político los empresarios del campo y de la agroindustria siguen siendo referentes de la economía nacional. 
E1 Presidente Juan Perón reconoce en 1951 que "lo justo es que ahora la independencia económica sirva al bienestar del campo argentino". ${ }^{x x v i i}$ No obstante, las malas cosechas de 1951-52 afectadas por la sequía acentúan la crisis económica del país y obligan al gobierno a explicitar sus definiciones. En 1952 anuncia el Plan Económico de Emergencia, proponiendo: aumentar la producción y reducir el consumo, revisar aquellas disposiciones sobre trabajo rural que impiden a los productores usar sus propios medios de transporte y solicita la colaboración de las organizaciones patronales y obreras para eliminar de los convenios colectivos toda circunstancia capaz de limitar la producción sin causa justificada. La estrategia de los sectores agrarios y agroindustriales da sus frutos. La política de precios agrarios anticipados, los subsidios agrícolas otorgados por el I.A.P.I., la rebaja en 2 puntos de las tasas de interés para el crédito agrícola y una mayor mecanización de las tareas rurales (Plan Trienal desde 1949 para importar tractores e implementos agrícolas) son medidas alentadoras para el sector, que sale fortalecido de la readecuación económica, al tiempo que deterioran la alianza intersectorial que respaldara el ascenso al poder de Juan Perón (FERRER, 1987, p. 53-81).

Durante el primer lustro de la década de 1950, el Estado hace menores concesiones a los asalariados del campo y reduce al mínimo su intervención para entregar la tierra en propiedad a los productores arrendatarios. Acciones que junto al viraje económico refuerzan el poder de los grandes propietarios, quienes tendrán un papel central en el derrocamiento de Perón durante setiembre de 1955 y en la política económica implementada por los hombres de la llamada "Revolución Libertadora", a partir de entonces y esencialmente con la vigencia del desarrollismo a partir de 1958. Los destinatarios principales del auxilio oficial son desde 1952: frigoríficos, grandes exportadores, agroindustriales, cooperativas agrarias, estancias, empresas productoras de maquinaria e instrumental agrícola (SCHVARZER, 1996, p. 196-224; GIRBALBLACHA, 2011).

Los sectores agrarios dejan registrada su conformidad con las resoluciones adoptadas por el Estado peronista, en su discurso. En enero de 1953 lo hace la Sociedad Rural Argentina, al expresar su beneplácito porque: "se aumentaron los precios oficiales para la carne; se facilitó y fomentó la compra e importación de maquinaria agrícola; se dieron normas sobre trabajo rural" y expresa su satisfacción porque "se fomentó la creación y el desarrollo de cooperativas rurales; se dio una nueva estructura al organismo oficial regulador del comercio de carnes, trasladándolo a la órbita del Ministerio de Agricultura de la Nación; se llegó a un feliz acuerdo con Gran Bretaña sobre comercialización de nuestra producción pecuaria exportable y se tomaron una serie de medidas oficiales, todas ellas encauzadas a estimular la producción rural 
al grado máximo". xxix Los acuerdos y coincidencias con el Estado se hacen públicos. El discurso oficial vira y se ajusta a los reclamos del empresariado rural. Perón admite que "la recuperación de la economía nacional de 1953 se originó en el sector de la producción agraria". xxx

\section{Representaciones de los intereses patronales rurales y agroindustriales: balance de sus continuidades y cambios}

El límite de la expansión horizontal agraria que se produce apenas iniciada la década de 1910 en la región pampeana argentina, modifica algunas estrategias tradicionales implementadas por los empresarios rurales en dos aspectos fundamentales: 1) la diversificación en las inversiones conforme al estilo adoptado desde los inicios del siglo XX; y 2) la organización corporativa en relación con el control social. Este contralor indelegable para quienes detentan el poder económico-político y el prestigio social, es el rasgo esencial de las representaciones de los intereses empresariales, patronales, así percibidas también por el Estado. Están dispuestos a mantener ese control a pesar de los cambios en el elenco de la política argentina, ocurridos debido a la aplicación de la Ley Sáenz Peña, que permite el ascenso del radicalismo y los sectores medios al gobierno nacional en 1916, también ante la ruptura institucional de los años '30 y - por último - frente al ascenso del peronismo al poder en 1946.

Los ajustes en los tradicionales mecanismos de control social impulsados desde el empresariado agroindustrial, forman parte de un necesario balance para comprender su lógica de acción interna, económica y política, así como sus relaciones con el Estado, en tanto representante de la sociedad en su conjunto e instrumento de los sectores hegemónicos. Instituciones específicas - que se distancian de las funciones propias de los partidos políticos como el Museo Social Argentino (1911), la CACIP (1916), la Asociación Nacional de Trabajo (1918), la Liga Patriótica Argentina (1919) y la Junta Nacional para Combatir la Desocupación (1935) en el marco referencial del nacionalismo de elite y frente al avance del intervencionismo estatal, advierten sobre la adecuación a los cambios para preservar el poder, estando o no al frente del gobierno.

Acerca del control social, las soluciones que se aportan derivan de las leyes de Residencia (1902) y de Defensa Social (1910), expulsoras de los extranjeros "perturbadores del orden público", según el Estado y los sectores patronales. Normas que se conjugan desde el Centenario con la racionalización de la inmigración, la acción institucional capaz de asegurar 
la contención del desempleo, la radicación de población en la campaña, la educación agraria para jóvenes y mujeres, el fomento de la colonización y la organización laboral.

La ruptura del orden institucional en la Argentina de 1930 y los efectos de la crisis internacional, promueven un Estado interventor, que subsidia al agro, flexibiliza el sistema financiero y regula el trabajo para contrarrestar la desocupación, la vagancia y la mendicidad. Las estrategias empresariales adecuadas a los tiempos, no cambian su acción de base. Su preocupación por contrarrestar el malestar social, aumentar sus ganancias y reclamarle protección al Estado, se mantienen constantes. Son ellos quienes - más allá de los cambios reclaman soluciones inmediatas a sus problemas al cada vez más poderoso Estado Nacional. Progresivamente, diversificando inversiones y alentando agroindustrias monoproductoras, en la Argentina, economía y política se corresponden.

Estado y empresarios del agro sostienen compromisos comunes y suelen coincidir en las estrategias operativas, por lo menos hasta el ascenso del peronismo al gobierno nacional, cuando se ponen en tela de juicio las atribuciones de los empresarios y la elite para conducir el proceso de control social. El "viejo orden rural" sufre una metamorfosis, pero conserva su poder tradicional aun ante la "reforma desde arriba" (HORA, 2002, p. 325-336). El Estado popular, dirigista y planificador refuerza su perfil nacionalista y reclama un lugar de liderazgo en la conducción de la "comunidad organizada". De todos modos, el empresariado rural recompone pronto su protagonismo en el escenario nacional y es el Estado quien aproxima su discurso al de los sectores patronales. Son éstos quienes exigen - y obtienen - protección y participación no sólo en la contención del malestar social y sus temidas secuelas, sino en las actividades económicas que les son propias. Así lo expresa la "vuelta al campo" desde 1950 (GIRBALBLACHA, 2016, p. 17-36).

Continuidades y cambios en las estrategias de los sectores empresarios agroindustriales durante la primera mitad del siglo XX, definen finalmente las permanencias de un estilo singular, pero siempre excluyente, marcando jerarquías de estos "defensores del control social". Son capaces de reacomodar el discurso y su accionar a los tiempos, sin renunciar a jugar una función organizadora y directriz en los problemas que vive la sociedad, mientras el Estado los respalda y avala más allá de su intervencionismo creciente en la economía, las finanzas y las acciones sociales.

\section{Referências}


ASCOLANI, A. El sindicalismo rural en la Argentina: De la resistencia clasista a lacomunidad organizada (1928-1952). Buenos Aires: Editorial Universidad Nacional de Quilmes, 2009.

BARBERO, M.; DEVOTO, F. Los nacionalistas. Buenos Aires: CEAL, 1983. (Biblioteca Política Argentina, 9).

BELLINI, C.; ROUGIER, M. El Estado Empresario en la industria argentina: Conformación y crisis. Buenos Aires: Manantial, 2008.

BLACHA, L. La clase política argentina (1930-1943): La oposición ausente y la pérdida de poder. Bernal: Editorial de la Universidad Nacional de Quilmes, 2015.

BLANCO, M. Reforma en el agro pampeano: Arrendamiento, propiedad y legislación agraria en la provincia de Buenos Aires 1940-1960. Buenos Aires. Editorial Universidad Nacional de Quilmes, 2007.

BOTANA, N. El orden conservador: La política argentina entre 1880 y 1916 . Buenos Aires: Editorial Sudamericana, 1977.

BRAVO, M. (Coord.). La agricultura: actores, expresiones corporativas y políticas. Tucumán: CFI-Gobierno de Tucumán, 2017. p. 69-98.

DE IMAZ, J. Los que mandan. Buenos Aires: Eudeba, Informes de Eudeba, 1965.

FERRER, A. Crisis y alternativas de la política económica argentina. Buenos Aires: Fondo de Cultura Económica, 1987. p. 53-81.

FERRER, A. y colaboración de ROUGIER, M. La economía argentina: Desde sus orígenes hasta principios del siglo XXI. Buenos Aires: FCE, 2008.

FINCHELSTEIN, F. Fascismo, liturgia e imaginario: El mito del general Uriburu y la Argentina nacionalista. Buenos Aires: FCE, 2002. Prefacio.

FISZBEIN, M. Instituciones e ideas en desarrollo: La planificación económica en la Argentina, 1945-1975. In: ROUGIER, M. (Director). Estudios sobre la industria argentina. Buenos Aires: Lenguaje Claro Editora, 2010. p. 15-50.

GIRBAL-BLACHA, N. Explotación forestal, riesgo empresario y diversificación económica: las inversiones argentinas en el Gran Chaco (1905-1930). Revista de Historia de América, México, IPGH, n. 116, p. 29-57, julio-dic. 1993.

GIRBAL-BLACHA, N. Azúcar, poder político y propuestas de concertación para el N.O.A. en los años '20: Las conferencias de gobernadores de 1926-192. Desarrollo Económico, Buenos Aires: IDES, v. 34, n. 133, p. 107-122, abril-junio 1994.

GIRBAL-BLACHA, N. Acerca de la vigencia de la Argentina agropecuaria: Estado y crédito al agro durante la gestión peronista (1946-1955). The Americas, Washington 3, v. 56, n. 3, p. 77-102, january 2000.

GIRBAL-BLACHA, N. Riqueza, poder y control social: Acerca de las estrategias empresariales agrarias en la Argentina (1900-1950). Anuario IEHS, Tandil, UNICEN, n. 18, p. 367-395, dic. 2003. 
GIRBAL-BLACHA, N. La Junta Nacional para Combatir la Desocupación: Tradición y modernización socioeconómica en la Argentina de los años treinta. Estudios del Trabajo. Buenos Aires, ASET, n. 25, p. 25-53, primer semestre 2003.

GIRBAL-BLACHA, N. Mitos, paradojas y realidades en la Argentina peronista (1946-1955): Una interpretación histórica de sus decisiones político-económicas. Bernal: Universidad Nacional de Quilmes Editorial, 2011. Primera reimpresión.

GIRBAL-BLACHA, N. Vivir en los márgenes: Estado, políticas públicas y conflictos sociales. El Gran Chaco Argentino en la primera mitad del sigloXX. Rosario: Prohistoria Ediciones, 2011.

GIRBAL-BLACHA, N. Perfiles históricos de la Argentina rural: agro y política (1880-1970). História: Debates e Tendencias, v. 16, n. 1, p. 17-36, jan./jun. 2016.

GIRBAL-BLACHA, N. La Liga Patriótica Argentina en el Congreso Nacional (1919-1960): La pervivencia del poder político entre bastidores. La Rivada, Revista electrónica de la Secretaría de Investigación y Posgrado, Posadas, FHyCS-UNaM, n. 10, p. 139-151, enero2018.

GUY, D. La industria argentina, 1870-1940: Legislación comercial, mercado de acciones y capitalización extranjera. Desarrollo Económico, Buenos Aires, IDES, v. 22, n. 87, p. 351374, oct./dic. 1982.

HORA, R. Los terratenientes de la pampa argentina: Una historia social y política 18601945. Buenos Aires: Siglo XXI de Argentina Editores, 2002.

LATTUADA, M. La política agraria peronista (1943-1983). Buenos Aires: CEAL, 1986. (Biblioteca Política Argentina 132/1).

LÁZZARO, S. La política y la reforma agraria en la Argentina, 1940-1970 ¿Hacia la destrucción del mito del terrateniente? In: BALSA, J.; MATEO, G.; OSPITAL, M. Pasado y presente en el agro argentino. Buenos Aires: Lumiére, 2008. p. 361-380.

LLACH, J. El Plan Pinedo de 1940, su significado histórico y los orígenes de la economía política del peronismo. Desarrollo Económico, Buenos Aires, IDES, v. 23, n. 92, p. 515-558, enero/marzo 1984.

MANZANAL, M.; NEIMAN, G.; LATTUADA, M. (compiladores). Desarrollo rural: Organizaciones, instituciones y territorios. Buenos Aires: Ediciones CICCUS, 2006.

MANZANAL, M.; ARZENO, M.; NUSSBAUMER, B. (comp.). Territorios en construcción: Actores, tramas y gobiernos: entre la cooperación y el conflicto. Buenos Aires: Ediciones Ciccus, 2007.

NOVICK, S. IAPI: auge y decadencia. Buenos Aires: CEAL, 1986. (Biblioteca Política Argentina, 136).

O'CONNELL, A. La Argentina en la Depresión: los problemas de una economía abierta. Desarrollo Económico, Buenos Aires, IDES, v. 23, n. 92, p. 479-514, enero/marzo 1984.

OSPITAL, M. Inmigración y nacionalismo: la Liga Patriótica y la Asociación del Trabajo (1910-1930). Buenos Aires: CEAL, 1994. (Biblioteca Política Argentina, 469).

PANETTIERI, J. Los trabajadores en tiempos de la inmigración masiva en Argentina, 18701910. La Plata: Universidad Nacional de La Plata, 1966. 
RAANAN, R. Peronismo, populismo y politica: Argentina 1943-1955. Buenos Aires: Editorial de Belgrano, 1998.

ROCK, D. El radicalismo argentino, 1890-1930. Buenos Aires: Amorrortu Editores, 1977.

ROUGIER, M. La economía del peronismo: Una perspectiva histórica. Buenos Aires:

Random House Mondadori-Sudamericana, 2012.

SÁBATO, J. La clase dominante en la Argentina Moderna. Buenos Aires: CISEA, 1989.

SCHVARZER, J. La industria que supimos conseguir. Buenos Aires: Planeta, 1996.

SIDICARO, R. Poder y crisis de la gran burguesía agraria en la Argentina. In: ROUQUIE, A. (comp.). Argentina hoy. Buenos Aires: Editorial Siglo XXI, 1982, p. 51-104.

VOVELLE, M. Histoire et representations. In: L'histoire aujourd'hui: Nouveaux objets de recherche. Courants et débats. Le métier d'historien. Paris: Editions Sciences Humaines, 1999 , p. 45-49.

ZANATTA, L. Del Estado liberal a la Nación Católica: Iglesia y ejército en los orígenes del peronismo. Bernal: Universidad Nacional de Quilmes, 1996.

ZIMMERMANN, E. Los liberales reformistas: La cuestión social en la Argentina. 18901916. Buenos Aires: Editorial Sudamericana-Universidad de San Andrés, 1994.

Submetido em: 11/10/2019

Aprovado em: 30/11/2019

Publicado: 23/12/2019

\section{Notas}

\footnotetext{
i Versión preliminar presentada a las VII Jornadas de Historia de la Industria y los Servicios. AEISEALUBA/UNSAM, setiembre de 2019.

ii Profesora y doctora en Historia, por la Facultad de Humanidades y Ciencias de la Educación de la Universidad Nacional de La Plata. Investigadora superior del Conicet. Profesora titular ordinaria y directora del Proyecto I+D "La Argentina rural del siglo xx" en la Universidad Nacional de Quilmes (UNQ). Directora de la colección Convergencia de la Editorial de la UNQ. Miembro de comisiones evaluadoras y asesoras en Ciencia y tecnología y de universidades nacionales y extranjeras. Académica de la Academia Nacional de la Historia y Miembro de Número del Instituto Histórico de la Manzana de las Luces de la Ciudad de Buenos Aires. E-mail: noemigirbal@gmail.com

iii Pedro G. Méndez, Luis E. Zuberbühler, Jacobo Kade, Hermann H. Schlieper, Emilio Palacio, Enrique Santamarina, Julius Haase, Cayetano Sánchez, Gorgonio Ramírez, Angel Ambrosetti, Carlos Carlés, Adolfo Villate. En Monitor de Sociedades Anónimas, 1905. Buenos Aires, 1906. BOLSA DE COMERCIO DE BUENOS AIRES. Memoria correspondiente al ejercicio de 1905. Buenos Aires, 1906, p. 33.

${ }^{\text {iv }}$ El millón de pesos oro se distribuye en 10.000 acciones de $\$ 100$ cada una. La vigencia estatutaria de la Sociedad es de 30 años. Integrantes: Ernesto Tornquist, D. De Tezanos Pinto, DomingoFunes, Jacobo Kade, L.H. Krüger, Otto Gaitzsch, Carlos Carranza, Carlos Schüssler, G.A. Schwenke y Enrique Berduc. In Monitor de Sociedades Anónimas 1906, Buenos Aires, 1907. INSTITUCIÓN TORNQUIST. Ernesto Tornquist. 1842-1942. Buenos Aires: E. Tornquist S.A, 1942, p. 32 y 39.

v CÁMARA DE DIPUTADOS DE LA NACIÓN. Diario de Sesiones. 1926. Buenos Aires, 1926, t. VI, p. 47.

vi JUNTA NACIONAL PARA COMBATIR LA DESOCUPACIÓN (Ley 11896). Memoria elevada al Ministerio del Interior. Buenos Aires, 1936, p. 7.
} 


\footnotetext{
vii Ibídem, p. 9.

viii Ibídem, p. 10 y ss.

ix Ibídem, p. 212.

${ }^{x}$ Ibídem, p. 212.

${ }^{x i}$ Ibídem, p. 123.

xii Ibídem, p. 123

xiii JUNTA NACIONAL PARA COMBATIR LA DESOCUPACIÓN. Memoria 1938-1939 y Conferencia Nacional de Coordinación del Trabajo reunida en Mendoza, 18-25 de marzo de 1939. Buenos Aires, 1939, t. 1, p. 66-67.

xiv Ibídem, p. 67.

xv Ibídem, p. 68.

xvi Ibídem, p. 215.

xvii JUNTA NACIONAL PARA COMBATIR LA DESOCUPACIÓN. Memoria 1938-1939 y Conferencia Nacional de Coordinación del Trabajo reunida en Mendoza, 18-25 de marzo de 1939. Buenos Aires, 1939, t. 2, p. 32.

xviii Ibídem, p. 36, 37.

xix Ibídem, p. 245-246.

xx Ibídem, p. 246.

xxi PRESIDENCIA DE LA NACIÓN. El campo recuperado por Perón (1944-1952). Buenos Aires, s/f, p. 11.

xxii CÁMARA DE SENADORES DE LA NACIÓN. Diario de Sesiones 1946. Buenos Aires, 1946, t. 1, p. 11.

xxiii SOCIEDAD RURAL ARGENTINA. Anales. Buenos Aires, marzo de 1948, p. 6-7; mayo de 1949, p. 31.

${ }^{x x i v}$ BANCO DE LA NACIÓN ARGENTINA. Memoria y balance general correspondiente al año 1949. Buenos Aires: B.N.A, 1950, p. 13.

xxv CÁMARA DE SENADORES DE LA NACIÓN. Diario de Sesiones 1950. Buenos Aires, 1950, v. 1, p. 17-18. xxvi BANCO DE LA NACIÓN ARGENTINA. Memoria y balance general correspondiente al año 1950. Buenos Aires, B.N.A, 1951, p. 21-23 y 51.

xxvii ARCHIVO DEL BANCO DE LA NACIÓN ARGENTINA. Libro de Actas del Directorio, núm. 169 (septiembre de 1950), f. 113.

xxviii CÁMARA DE SENADORES DE LA NACIÓN. Diario de Sesiones 1950. Buenos Aires, 1950, p. 20. Ibídem, 1951. Buenos Aires, 1951, v. 1, p. 10.

xxix SOCIEDAD RURAL ARGENTINA. Anales. Buenos Aires, enero de 1953, p. 7.

${ }^{x x x}$ La Res. Buenos Aires, n. 467, 20 de junio de 1953, p. 28076-28081.
} 